Article

\title{
Biofuels and Sustainable Transport: A Conceptual Discussion
}

\section{Erling Holden ${ }^{1, *}$ and Geoffrey Gilpin ${ }^{2}$}

1 Department of Civil and Transport Engineering, Norwegian University of Science and Technology, NTNU, Trondheim 7491, Norway

2 Western Norway Research Institute, PO Box 163, Sogndal 6851, Norway; E-Mail: geoffrey.gilpin@vestforsk.no

* Author to whom correspondence should be addressed; E-Mail: erling.holden@ntnu.no; Tel.: +47-73-59-46-40; Fax: +47-73-59-70-21.

Received: 13 May 2013; in revised form: 13 June 2013 / Accepted: 15 July 2013 /

Published: 22 July 2013

\begin{abstract}
Strategies for sustainably using biofuels must be thoroughly assessed at several levels. First, the use of biofuels must comply with sustainable development's main dimensions. Second, the use of biofuels must comply with sustainable transport's main dimensions. Third, gains from using biofuels strategies must compare favorably to gains from other sustainable transport strategies, such as altering transport patterns and reducing transport volume. Fourth, the gains must compare favorably to gains from improving conventional fossil-fuel-based advanced vehicles. Fifth, the gains must compare favorably to gains from using other alternative fuels. Sixth, the gains from using one generation of biofuels (e.g., first generation) must compare favorably to gains from using others (e.g., second through fourth generations). Performing scientifically sound and fair comparisons demands reliable theoretical perspectives and a well-established methodological basis. Industrial ecology theory and life cycle assessment methodology, respectively, are well-suited for these tasks.
\end{abstract}

Keywords: ecological sustainability; sustainability assessment and strategies; biofuels; sustainable development; sustainable transport; industrial ecology; life cycle assessment 


\author{
Abbreviations \\ ALCA: attributional LCA \\ CLCA: consequential LCA \\ GHG: greenhouse gas \\ ICE: internal combustion engine \\ IEA: International Energy Agency \\ ISO: International Organization for Standardization \\ LCA: life cycle assessment \\ LCA-IO: input-output macro-economic model \\ LCSA: life cycle sustainability analysis \\ MRIO: multi-regional input-output \\ OECD: the Organisation for Economic Co-operation and Development \\ UNEP: United Nations Environmental Programme \\ RED: Renewable Energy Directive \\ WIO: waste input-output \\ WTM: world trade model
}

\title{
1. Introduction
}

Climate change impacts, together with an increasing demand for energy, volatile oil prices, and energy poverty have led to a search for energy options that will be economically efficient, socially equitable and environmentally sound. One option that has raised significant interest from a wide range of actors is increased use of biofuels. Encouraged by research indicating that biofuels could provide substantial energy while at the same time mitigating climate change, governments have supported production aimed at increasing biofuel use in many countries. Farmers seek additional income, and biofuels may have the potential to promote rural development and access to energy in poorer countries. Industry has invested significantly in production and technology development. The number of scientific publications devoted to biofuels is growing rapidly, as is the number of reviews [1]. Thus, the use of biofuels is seen as an important pathway to achieving sustainable transport.

However, there are major concerns about the negative implications of growing biomass for biofuel production. Currently, biofuels are often made from feedstock crops that also serve as food. Hence, there is a potential risk for competition between food and fuel, which could result in consequences on food prices. Another identified risk is expansion of biofuel feedstock production into ecosystems that support high biodiversity and other services that are crucial to our economies and human life. Moreover, the envisaged positive effects on climate mitigation could turn out to have the opposite effect because of land-use changes associated with expanding agriculture [1].

Thus, two important issues regarding the merits of biofuels must be addressed. Are biofuels really sustainable; that is, do they comply with the main dimensions of sustainable development? Moreover, how do they compete with other strategies and technologies to comply with these dimensions? The aim of this paper is to provide a framework for assessing these issues with a particular focus on sustainable transport. 
We argue that an assessment of the merits of biofuels requires discussions at six levels (Figure 1). As a starting point, the main dimensions of sustainable development must be defined. To meaningfully interpret sustainable transport, we must sort out these dimensions. Second, we must translate these dimensions into transport dimensions, giving relevant substance to the sustainable transport concept. Third, we must outline the competing strategies for achieving sustainable transport. The strategies are efficiency (e.g., developing improved fuels and technologies), alteration (e.g., promoting mode shifts) and reduction (e.g., avoiding trips) [2]. Fourth, we must compare technology strategies. At this level, the relative merits of conventional and alternative fuels are compared. Fifth, we must compare the relative merits of various alternative fuels. A large number of alternative fuels (e.g., biofuels, electricity, and hydrogen) have been suggested as appropriate solutions, and their respective qualities must be compared and assessed. Sixth, we must discuss and compare the various generations of biofuels. Biofuels can originate from various sources (e.g., sugar cane, wood, or algae), take different forms (e.g., gas or liquid), and use different technologies (e.g., ICEs or fuel cells). Additionally, we must find appropriate theoretical perspectives (e.g., industrial ecology) and methods (e.g., LCA) to make sustainability assessments at each level.

To assess the comparative merits of a specific solution at a given level (e.g., promoting second-generation biofuels at level 6), two questions must be addressed. (1) How does this solution compare to other solutions at the same level? (2) How does this solution compare to solutions at higher levels?

A comprehensive assessment at each level can hardly be done in one article. Rather, we discuss some of the main issues at each level and present a few examples to illustrate how assessments can be made. We focus on passenger mobility, but many of the conclusions may eventually be relevant for goods transport as well. Moreover, the arguments are based from a Western (European) point of view. Yet, sustainable transport is a global challenge and therefore throughout the article the challenge of achieving sustainable transport in both developed countries and developing countries is addressed. Thus, our conclusions may turn out to be relevant for a number of developing countries as well.

\section{Sustainable Development}

Sustainable development has increasingly been presented as a pathway to all that is good and desirable in society. The list of proposed indicators is long, and it grows longer yearly. Thus, the sustainable development concept has become so comprehensive and complex that it is becoming less helpful in guiding policymaking. Not surprisingly, a number of scholars have argued that the sustainable development concept is about to become useless, if it has not already done so.

Even though there is not yet any political or scientific agreement on a definition of sustainable development, it remains remarkably persistent as an ideal political concept, similar to democracy, justice, and liberty [3]. Indeed, sustainable development "is now like 'democracy': it is universally desired, diversely understood, extremely difficult to achieve, and won’t go away” [4].

Unquestionably, sustainable development still is an important concept, which was clearly illustrated at the United Nations Conference on Sustainable Development, held in Rio de Janeiro in June 2012. One of the conference's main outcomes was the agreement by member states to set up sustainable development goals, which could be useful tools in achieving sustainable development. Thus, achieving 
sustainable development is still high on the international and national agendas 25 years after the concept was launched with the publication of Our Common Future, commonly referred to as the Brundtland Report [5].

Figure 1. Sustainable development (SD), sustainable transport (ST) and biofuels.

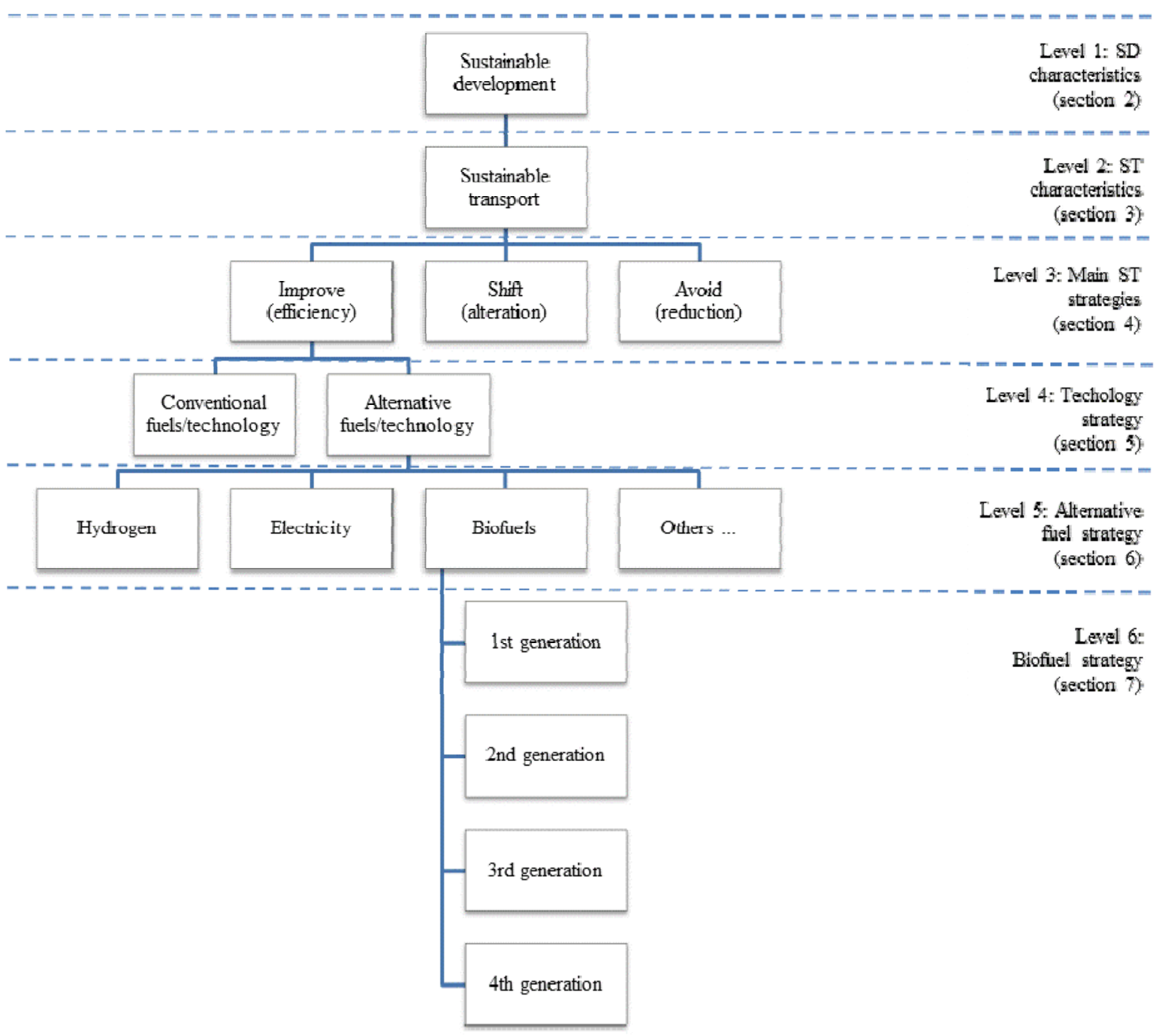

Notes: (i) Level 1 to 6 represent a hierarchy of biofuels and sustainable development relations; theoretical perspective and methods represent one way of assessing the relations; (ii) Reference to article sections in brackets on the right-hand side in the figure; (iii) Main ST strategies: Improve (efficiency) = using new, conventional and/or alternative technology; Shift (alteration) = changing the prevailingly transport pattern into one based on public transport systems; Avoid (reduction) = decreasing present transport volume.

However, to become a useful tool, the concept must be clearly defined. Four main dimensions can be derived from the Brundtland Report: (1) safeguarding long-term ecological sustainability, (2) satisfying basic human needs, and promoting (3) intragenerational and (4) intergenerational equity [6]. These dimensions are what Daly refers to as "fundamental objective values, not subjective individual preferences" [7]. Thus, they are not negotiable. 
In addition to the main dimensions, Høyer [8] presents a number of secondary dimensions, which include preserving nature's intrinsic value, promoting protection of the environment, promoting public participation, and satisfying aspirations for an improved standard of living (or quality of life). These secondary dimensions are subordinate to the main dimensions. Thus, preserving nature's intrinsic value (a secondary dimension) must give way whenever basic human needs (a main dimension) are threatened. Correspondingly, satisfying aspirations for a better life (a secondary dimension) should be subordinate to safeguarding long-term ecological sustainability (a main dimension).

\section{Relevance for Biofuels}

The use of biofuels clearly has relevance for all four main dimensions. Biofuels' potential to reduce GHG emissions and thereby safeguard long-term ecological sustainability is one of the reasons why biofuels have been introduced in the first place. Indeed, given the right conditions, biofuels have been shown to have a great potential to reduce GHG emissions.

The "food or fuel" debate clearly shows that biofuels have relevance to satisfying basic human needs [1]. Concern has been growing about negative implications of growing biomass for biofuel production. As stated previously, there are concerns with concern to food and expansion of production into valuable ecosystems.

The relevance to equity is twofold. First, biomass feedstock for biofuels production is readily available in most countries and could promote intragenerational equity. Second, biofuels are continuously renewable and could promote intergenerational equity. The main point, however, is that biofuels' merits must be assessed across all of these dimensions.

This point has been acknowledged for some time though, for example in the 2006-2009 Bioethanol for Sustainable Transport project [9]. Yet, the current overall trend is that, as policies surrounding biofuels (and more generally bioenergy) become more holistic, sustainability has become a stronger criterion at the starting point of policy development $[10,11]$. This has occurred in the EU, the USA and China, but also in many developing countries such as Mozambique and Tanzania. There are now more than 70 registered initiatives worldwide to develop and implement sustainability frameworks and certification systems for bioenergy and biofuels, as well as in agriculture and forestry (more on this in Section 7), but this can also lead to a fragmentation of efforts [10]. The four dimensions presented here should perform as guidelines for all such initiatives.

\section{Sustainable Transport}

Since launching their 1992 Green Paper on the Impact of Transport on the Environment, the EU has had sustainable transport as an overriding goal in its transport policy [12,13]. Since then, the EU has continued pursuing this goal in two White Papers [14,15].

Still, as the EU emphasizes in their 2011 White Paper, the transport system is not sustainable: "Looking 40 years ahead, it is clear that transport cannot develop along the same path. If we stick to the business as usual approach, the oil dependence of transport might still be little below 90\%, with renewable energy (hereafter, $\mathrm{RE}$ ) sources only marginally exceeding the $10 \%$ target set for $2020 . \mathrm{CO}_{2}$ emissions from transport would remain one third higher than their 1990 level by 2050. Congestion costs will increase by about $50 \%$ by 2050 . The accessibility gap between central and peripheral areas 
will widen. The social costs of accidents and noise would continue to increase” ([14], p. 4). Thus, finding ways to make transport sustainable remains high on the political agenda.

In fact, in most developed countries, the present transport patterns are unsustainable [16-21]. Moreover, there is still no political or scientific agreement on a definition of sustainable transport or on the required policies to achieve it. Rather, the use of the concept has increasingly reflected socially desirable attributes of local- and project-level problem solving, ignoring the global challenges that the concept was meant to solve [19]. To reflect local or project-specific challenges, a diversity of definitions and interpretations of the concept has been presented in the literature with the risk that the concept has become diluted and will end up as mere rhetoric offering little actually guidance for policymakers and scientists [19].

However, the main dimensions for sustainable transport can be derived from each of the main dimensions for sustainable development, thereby ensuring that the concept of sustainable transport reflects the four main dimensions of sustainability as described in the Brundtland Report. Thus, we argue that the main dimensions of sustainable transport are that it establishes [19]:

- an upper limit on daily per capita energy consumption for passenger transport to safeguard long-term ecological sustainability;

- a lower limit on daily per capita travel distance for motorized transport to satisfy basic transport needs;

- a minimum fraction of the total population that must have accessibility to public transport to promote intragenerational transport equity; and

- a minimum fraction of transport fuel that must be provided from RE sources to promote intergenerational transport equity.

We argue that the four main dimensions (e.g., safeguarding long-term ecological sustainability) and their corresponding indicators (e.g., per capita energy consumption for passenger transport) represent equally important targets where each needs to be fulfilled. This excludes the possibility of trading off an underperformance on one indicator against an over performance on another. Transport policies must reflect this; for example, will an affordable, biofuel-based public transport system reduce per capita energy consumption, satisfy basic transport needs for all population groups and promote RE sources.

Other important dimensions of sustainable transport certainly exist, for example, minimizing noise and reducing congestion. However, focusing on these less important dimensions (that is, "secondary dimensions") rather than on addressing the four main ones will not enhance the core concerns of sustainable transport.

\section{Relevance for Biofuels}

The first dimension creates two problems for biofuels. First, some biofuel varieties do not provide a net energy gain-more energy is required to produce the fuels than they provide [1]. Second, many types of biofuels depend on the use of fossil fuels for harvest, production and distribution [10].

The second dimension raises the question of potential and limitations. We need to remember that renewable (in time) should not be confused with limitless (in volume). Estimates of the global long-term bioenergy potential depend critically on assumptions, particularly on the availability of 
agricultural land for non-food production. Whereas more optimistic assumptions lead to a theoretical potential of 200-400 EJ/year or even higher, the most pessimistic scenario relies only on the use of organic waste and residues, providing a minimum of $40 \mathrm{EJ} /$ year. More realistic assessments considering environmental constraints arrive at a sustainable potential of 40-85 EJ/year by 2050 [1]. For comparison, predicted global energy demand for transport that year totals 140 EJ/year [22].

Additionally, other production factors are also involved in addition to resources, for example, labor and capital, whose limits may be exceeded sooner than those of resources. Studies have shown that labor and capital are equally important factors concerning the level of production and prices of products and services [23].

The third dimension raises no particular issues in terms of biofuels; numerous studies have shown that biofuels work well in public transport. The fourth dimension generally favors biofuels, provided they are not dependent on fossil fuels for their production.

\section{Main Sustainable Transport Strategies}

A review of the literature reveals three main sustainable transport strategies: efficiency, alteration and reduction [19,24] (level 3 on Figure 1). These three strategies, under different names, represent established knowledge within the sustainable transport (and sustainable development) literature [25], for example, the IPAT equation [26,27], the ASIF equation [28], the ISA model [29]; the SMART model [19]; social, technical, and infrastructural emission drivers [30]; and the STPM index [31].

The efficiency strategy for achieving sustainable transport suggests that the environmental problems caused by transport can be reduced and that the lack of accessibility for low-mobility groups can be relieved by developing more efficient technology. The concept of "technology" is here used in a broad sense; it includes the use of both "hard technology" (e.g., developing more efficient vehicle technology and fuels) and "soft technology" (e.g., developing more efficient transport logistics). Moreover, technology that is more efficient could be implemented across all parts of the transport system: motorized transport, transport infrastructure and the energy system.

The alteration approach recognizes the urgent need to fundamentally change present transport patterns. Accordingly, the prevailingly transport pattern, dominated by cars and planes, must be changed into one based on collective forms of transport, primarily affordable well-functioning public transport systems [32]. Such systems would lead to increased use of buses, trains and trams, which are all more energy efficient than cars and planes, and therefore reduce the use of cars and planes. Moreover, an affordable well-functioning public transport system would increase accessibility for low-mobility groups.

The reduction approach for achieving sustainable mobility does not question the importance of improved efficiency and increased alteration. Indeed, the latter two approaches would, according to the reduction approach, offer some reductions in energy consumption. However, these reductions are not large enough to meet sustainable transport's energy goal. Moreover, continuous transport growth negates any reductions in energy consumption achieved by implementing new technology and altering transport patterns. Thus, the present transport volume must be decreased-except for those whose basic transport needs are not met—or at least transport growth trends must be changed. 


\section{Relevance for Biofuels}

Biofuels belong to the efficiency strategy, but it is interesting to know the role they will play as part of the larger picture of looking at all three strategies. A study by the OECD [33] offers some insight on this matter. In their Environmentally Sustainable Transport (EST) project, they constructed three sustainable transport scenarios to illustrate the respective importance of the three strategies. The results from what they regarded the most realistic scenario, EST 3, are illustrated in Figure 2.

Figure 2. The relative importance of each sustainable transport strategy in achieving sustainable transport [33]. (The figure shows results from OECD’s EST 3 scenario.)

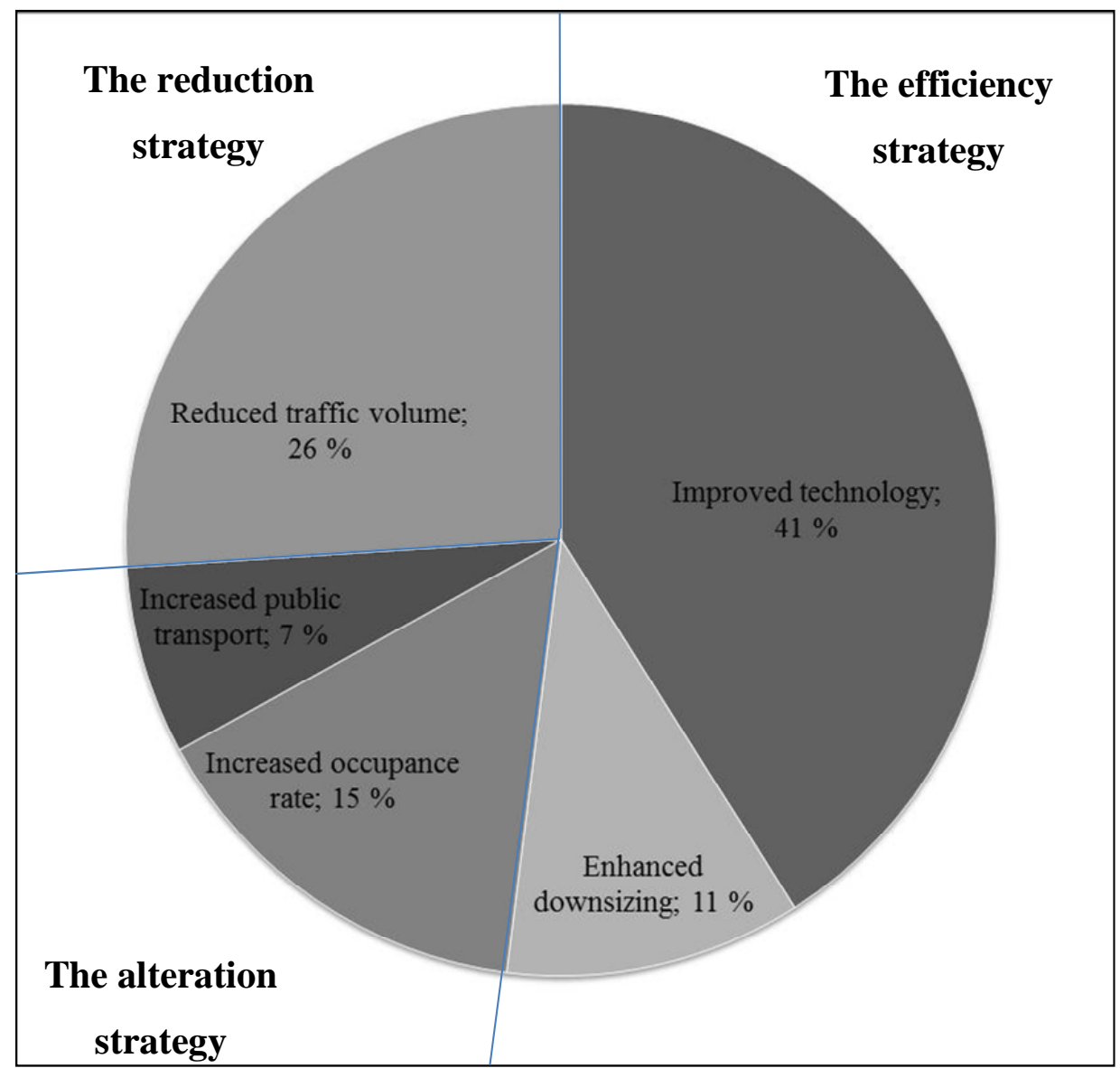

Note: The first two phases of the four-phase EST project established a definition of EST and selected criteria for its attainment (phase 1), and constructed EST scenarios (phase 2). Six criteria were selected: CO2, NOX, VOXs, particulates, noise and land use. Three scenarios were developed for 2030 (that differentiated from the business-as-usual (BAU) scenario): EST1, EST2 and EST3. Each scenario used different assumptions regarding technological progress and transport activity level. 30. Although all three EST scenarios met the EST criteria, the first two scenarios appeared to be too extreme. The EST1 scenario seemed to involve unacceptable economic costs, and the EST2 scenario seemed to involve unacceptable social costs. Accordingly, the research team decided that further work should be confined to assessing how the EST3 scenario might be attained, and to comparing the EST3 and the BAU scenario. It is important to note that the EST3 scenario differs from the BAU scenario in two ways: It implies greater technological progress and less transport activity than the BAU scenario. 
An obvious conclusion that can be drawn from the OECD study is that improved technology contributes less than half of what is required to achieve sustainable transport. Thus, the OECD claims that improved technology is a necessary, but insufficient, strategy for achieving sustainable transport.

This claim is supported by Sager et al. [30]. In their 2050 light-duty vehicle scenarios, they forecast that meeting GHG emissions targets (an important part of safeguarding long-term ecological sustainability) through technological improvements (i.e., the efficiency strategy) alone would require universal deployment of one or more of the following clusters: electric vehicles running on nearly zero-carbon electricity, cellulosic biofuel-powered vehicles achieving $0.78 \mathrm{~L}$ per $100 \mathrm{~km}$, or gasoline-fuelled vehicles achieving in excess of $0.24 \mathrm{~L}$ per $100 \mathrm{~km}$. The researchers argue that these performance levels exceed even the most optimistic technology scenarios for the year 2050. Thus, they claim that reducing GHG emissions is also a behavioral issue (i.e., alteration and reduction), not only a technological (efficiency) one.

\section{Technology Strategies}

The efficiency strategy can further be divided into two main sub-strategies: (1) the use of new, conventional technology and (2) the use of alternative technology [19] (level 4 on Figure 1). The strategy of using new but conventional technology seeks incremental improvements in existing transport technology, such as advanced ICE with direct injection, energy-efficient hybrid-drive systems, improved catalytic converters, reduced vehicle weight using lightweight materials, advanced motor management, improved aerodynamics, reduced rolling resistance and improved low-sulfur diesel fuel. The alternative strategy seeks to implement fundamentally new transport technology, such as introducing new fuels (biofuels and hydrogen) and drive systems (fuel cells).

The current liquid transport-fuel market is dominated by conventional fuels and technology. Taking into consideration the expected future increase in demand from all transport sectors, and the current and foreseen dominance of the ICE, the demand for liquid transport fuels can be expected to persist; therefore, biofuels offer an appealing means of achieving sustainable transport in the near future $[34,35]$.

\section{Relevance for Biofuels}

Government policies in various countries have led to a five-fold increase in global biofuel production from 2000 to 2008. Consequently, biofuels, whether pure or blended, accounted for $2 \%$ of global road transport-fuel demand in 2008. The production of ethanol and biodiesel increased by $10 \%$ and 9\%, respectively, in 2009, to 90 billion liters. Biofuels contributed nearly 3\% (3 EJ) of global road transport-fuel demand in 2009 [10].

The projected biofuel share needed by 2030 and 2050 have been estimated to be close to $10 \%$ (12 EJ per year) and 15\% (20 EJ per year), respectively [10,36].

\section{Alternative Fuel Strategy}

There are a number of possible pathways from the conversion of a primary energy source to an energy carrier (fuel) that can be used to power a vehicle. Possible pathways are shown in Figure 3, 
where alternative technologies and fuels include all but those that rely on conventional, oil-based gasoline and diesel. Note that alternative fuels include many varieties based on fossil energy sources, for example, coal-based methanol and electricity (level 5 in Figure 1). Thus, fuels based on RE sources constitute a particular sub-group of the broad category of alternative fuels.

Figure 3. Possible pathways from primary energy sources to vehicular use [10].
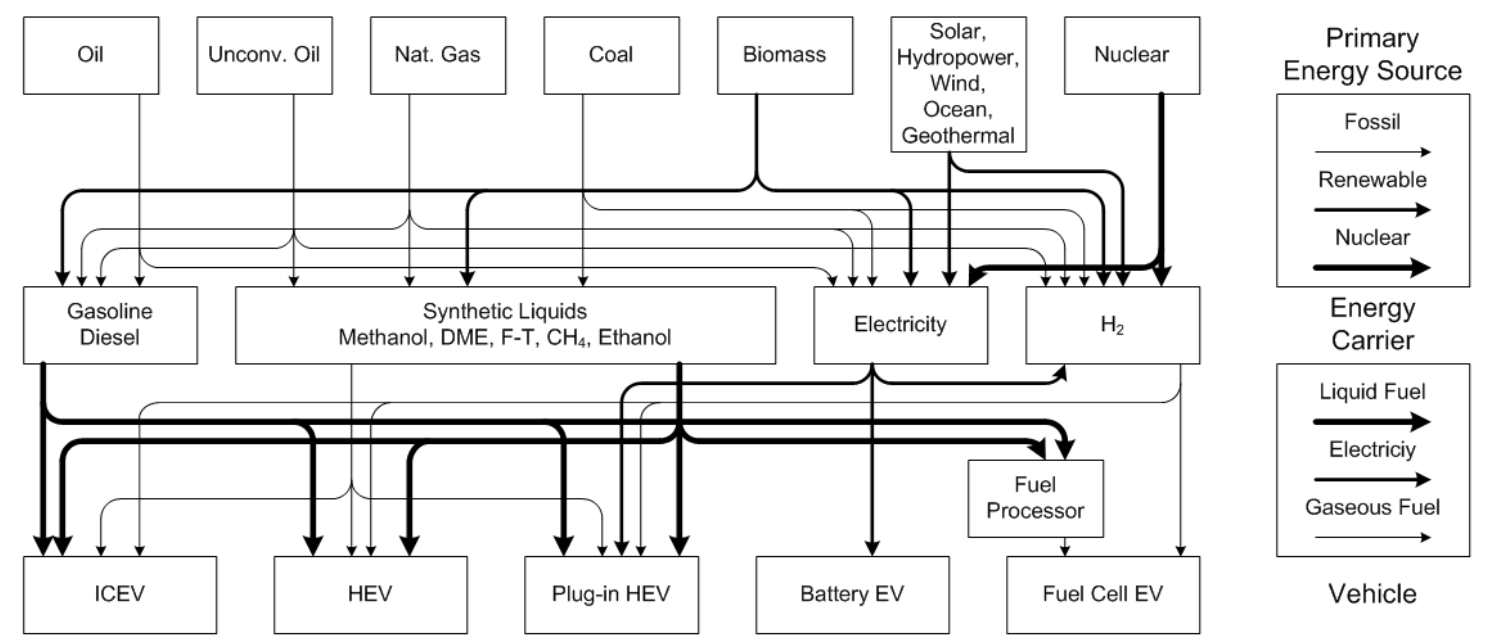

Notes: F-T $=$ Fischer-Tropsch process. DME $=$ Dimethyl ether. "Unconventional oil" refers to oil sands, oil shale, and other heavy crudes. ICEV = internal combustion engine vehicles, HEV = hybrid electric vehicles, and $\mathrm{EV}=$ electric vehicles.

The IEA (2009) has recently given a good deal of consideration to the impact of alternative fuels and their corresponding compliance with sustainable development. In their Alternative Motor Fuels Platform, the IEA supports extending sustainability criteria beyond environmental indicators and gives the consensual criteria by which any alternative fuel use should be evaluated [37]: (1) it should provide a net energy gain, that is, not use more energy to produce the fuel than it provides; (2) it should provide environmental benefits; (3) it should be economically competitive; and (4) it should be producible in sufficient quantities without impacting the availability or price of the same feedstock when used as food. Preferably, the use of the feedstock for fuel would not compete with its use for food.

\section{Relevance for Biofuels}

All these criteria are highly relevant for biofuels. We would argue, however, that demanding that biofuels be "economically competitive" constitutes a necessary means rather than a goal in itself.

\section{Biofuel Strategy}

Applying the general precept of sustainable development to the more specific case of biofuels for transport (level 6 in Figure 1) has given rise to a new set of challenges. First, a number of different generations of biofuels must be evaluated. Second, there are a large number of impact assessment frameworks, standards, sustainability criteria, and certifications by which competing generations of biofuels can be evaluated. We discuss both of these challenges briefly here. 


\subsection{From First- to Fourth-Generation Biofuels}

Biofuels for transport are commonly labeled as first-, second- or third-generation biofuels, respectively [1]. Second- and third-generation biofuels are also sometimes labeled "advanced," "next-generation," or "modern" biofuels [10]. This differentiation in generations is not always straightforward, however, because of overlaps in terms of feedstock and processing technologies, as well as uncertainties about environmental impacts.

Many definitions of first to third generations are presented in the literature; UNEP suggests the following definitions [1] (Figure 4).

Figure 4. Current and emerging biofuel pathways [1].

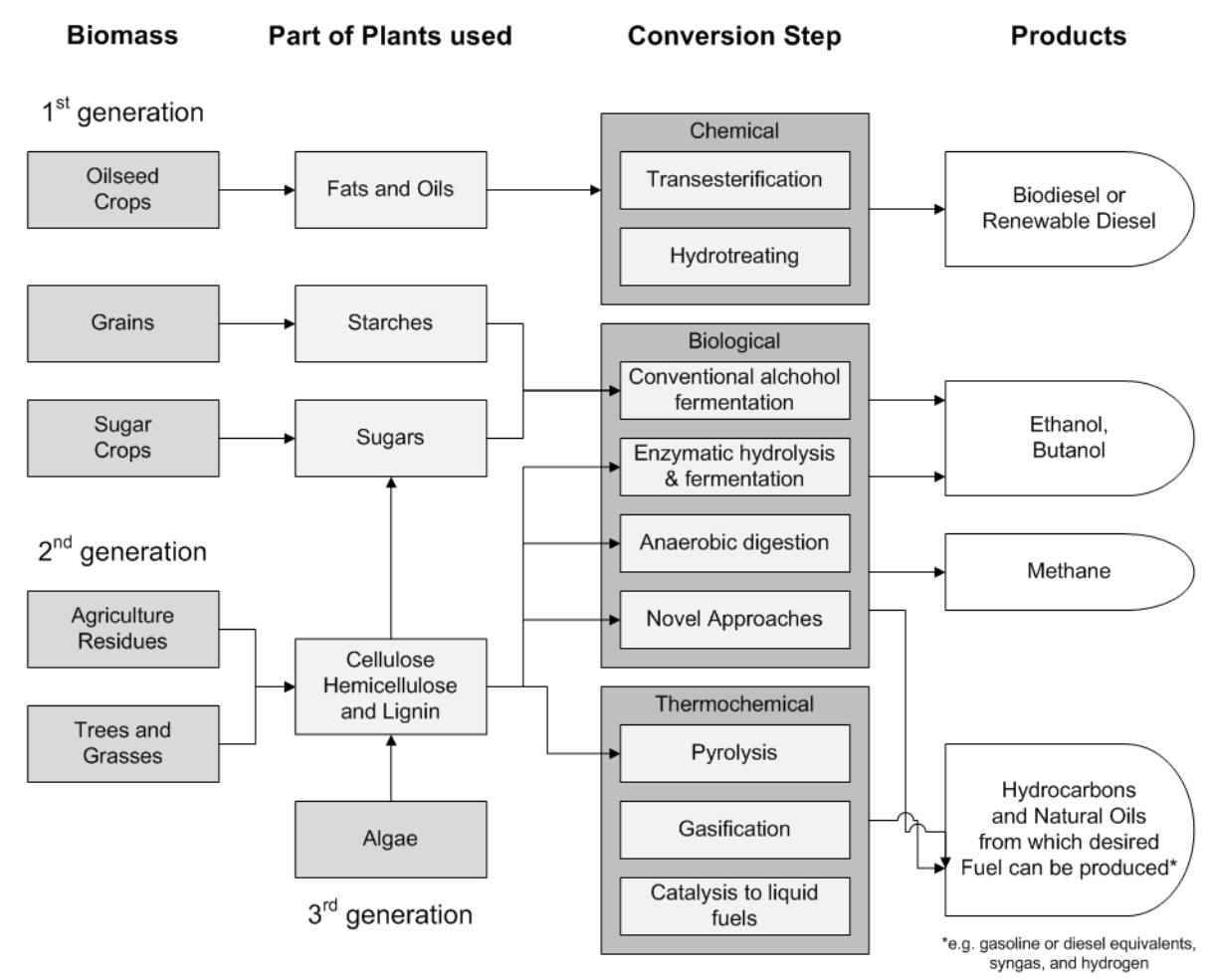

Note: Fourth-generation biofuels are not shown in the figure. 1st generation would also include waste oil (not shown in figure). 2nd generation "Trees and Grasses" include both residues and dedicated crops.

First-generation biofuels are commercially produced using conventional technology. The basic feedstocks are seeds, grains or whole plants from crops such as corn, sugar cane, rapeseed, wheat, sunflower seeds or oil palm. These plants were originally used as food or fodder, and most are still primarily used to feed people. The most common first-generation biofuel is bioethanol, followed by biodiesel, vegetable oil and biogas.

Second-generation biofuels can be produced from a variety of non-food sources. These include waste biomass, the stalks of wheat, corn stover, wood and special energy or biomass crops. Second-generation biofuels use biomass-to-liquid technology through thermochemical conversion (mainly to produce biodiesel) or fermentation (e.g., to produce cellulosic ethanol). Many second-generation biofuels are under development, including biohydrogen, biomethanol, dimethylfuran, bio-dimethyl ether, Fischer-Tropsch diesel, biohydrogen diesel and mixed alcohols. 
Third-generation biofuels, also called oilgae, are produced from algae. The algae are feedstock derived from aquatic cultivation for the production of triglycerides (from algal oil) to produce biodiesel. The processing technology is basically the same as that used for biodiesel from second-generation feedstock. Other third-generation biofuels include alcohols such as bio-propanol or bio-butanol, which because of the current lack of production experience, are usually not considered to be relevant as fuels on the market before 2050 [1], although increased investment could accelerate their development. The same feedstock as that used for first-generation ethanol can be used, but its use requires more sophisticated technology.

Although not shown on Figure 4, some have expanded this field to include fourth-generation biofuels [38-40] through the use of genetically modified feedstocks or the use of targeted synthetic microbes to produce synthetic or carbon-negative biofuels. This type of genetic modification has, however, raised serious concerns about the potential environmental impacts of such plants, including gene flow from non-native to native plant relatives [41-43].

Each succeeding generation of biofuel has been developed to reduce the disadvantages and improve on the advantages of the proceeding generation, although as can be expected, each new generation has given rise to new challenges. This complex situation has been noted in the EU relative to the use of second-generation biofuels [44]. Here, the advantages of improved GHG balance, cost competitiveness, fuel quality, land use and food production are stated relative to those of first-generation biofuels in the same characteristics. The same summary states that the challenges confronting second-generation biofuels are primarily related to technology and infrastructure. A European roadmap for biofuels [45] presents a similar mixture of advantages and challenges for first- and second-generation biofuels, and additional studies have presented similar discussions concerning third-generation biofuels [46].

\subsection{Sustainability Frameworks, Standards, Criteria and Certification}

Governments are stressing the importance of avoiding unacceptable negative effects of bioenergy as they implement regulating instruments. For example, the RED [47] provides mandatory sustainability requirements for liquid transport fuels. Also, in the United States, the Renewable Fuel Standard (included in the 2007 Energy Independence and Security Act [48]) mandates minimum GHG emission reductions from the use of renewable fuels, discourages the use of food and fodder crops as feedstock, permits the use of cultivated land and estimates the effects of land-use change [49] to set thresholds of GHG emission reductions for different categories of fuels [10]. The California Low Carbon Fuel Standard set an absolute carbon intensity reduction standard and periodic evaluation of new information, for example, on indirect land-use impacts. Other examples of this type of regulatory instrument are the UK Renewable Transport Fuel Obligation, the German Biofuel Sustainability Ordinance and the Netherland NT8080 (also known as the Cramer Report).

The development of impact assessment frameworks and sustainability criteria involves significant challenges in relation to methodology, process development and harmonization. As of a 2010 review, nearly 70 ongoing efforts existed to safeguard the sustainability of agriculture and forestry products, including those used as feedstock for the production of bioenergy and biofuels [50]. However, the majority of efforts focus on environmental impacts, which is problematic because of the conflicts that arise between socioeconomic and environmental impacts, especially in developing countries [10,11]. 
This is going to change though. A review shows that there are (at least) twelve standards and systems currently under consideration worldwide [11]: Rainforest Alliance: Sustainable Agriculture Network; Program for Endorsement of Forest Certification; Social Accountability International; Roundtable on Responsible Soy; Roundtable on Sustainable Palm Oil; The Forest Stewardship Council; Roundtable on Sustainable Biofuels; Better Sugar Initiative; Argentinian Association of Producers for No Tillage; The International Social and Environmental Accreditation and Labeling Alliance; Fair Trade Organization; The Global Bioenergy Energy Partnership; and International Sustainability and Carbon Certification.

The increase of standards that has taken place over the past four years and that continues to advance, shows that certification has the potential to influence local impacts related to the environmental and social effects of direct bioenergy production. Many involved entities conclude that to create an efficient certification system there must be further harmonization, greater availability of reliable data and increased linking of indicators at the micro (e.g., product), meso (e.g., household or municipality) and macro (e.g., economy of states) levels [10].

Thus, sustainability criteria and biomass and biofuels certification have been developed in increasing numbers in recent years as part of voluntary or mandatory systems; interestingly, such criteria do not yet apply to conventional fossil fuels.

\section{Theoretical Perspectives and Methodology}

Performing scientifically sound and fair comparisons at each of the six levels demands a reliable theoretical perspective and a well-established methodological basis (bottom of Figure 1). We argue that industrial ecology theory and LCA methodology provide such a basis. Industrial ecology acknowledges the complexity and trade-offs involved in comparisons at each level and, moreover, provides input to policies surrounding biofuels in a holistic way. LCA gives quantitative weight to the comparisons. True, LCA can and should be supplemented by other methodologies and environmental management tools in line with industrial ecology, such as social impact assessment, strategic environmental assessment and sustainability assessment. However, this article focuses on LCA.

\subsection{Transfer Effects and Industrial Ecology}

Particular problems, referred to as "transfer effects," occur when assessing the sustainability of biofuels (and of alternative fuels generally). Such effects have two forms [51].

Geographic transfer effect: The use of alternative fuels merely transfers energy consumption and emissions geographically (i.e., from the vehicle to the production site and the distribution process); it does not reduce total energy consumption or emissions $[1,10,19]$.

Thematic transfer effect: There are always trade-offs involved in using alternative fuels because their use merely changes environmental impacts thematically rather than reducing the total overall environmental impacts [1,19].

Transfer effects can be positive or negative. Geographical transfer can be justified as shifting emissions from urban to less-populated areas and thereby reducing exposure and the associated impacts on human health. Despite increases in total emissions, some bioethanol blends used in flex-fuel vehicles in Brazil contributed to reductions of as much as $30 \%$ in urban emissions because 
most emissions originated from farming equipment, fertilizer manufacture and ethanol plants located in rural areas [52]. Thematic transfer can be justified by reducing one particularly important negative impact while at the same time accepting an increase in another less important negative impact.

The occurrence and implications of transfer effects are only evident when one adopts a holistic approach to evaluation, as promoted in the field of industrial ecology. Industrial ecology tries to address the issue of sustainable development within the context of the interrelations between the environment, the economic sphere and the techno sphere. This approach draws on an analogy with natural ecosystems, in which a web of connection exists through which individual organisms live and consume each other and each other's waste [53]. Similarly, industrial ecology can be considered the study of a pattern, or web, of relationships between various industrial activities, their products and the environment with which they interact [54].

One of the important aspects addressed by industrial ecology is that the whole life cycle, including waste and disposal, must be considered in the design process. This cradle-to-grave production philosophy is ideally represented by the unique case in which there is no grave, that is to say, by industrial processes that are environmentally benign during their whole life cycle, including manufacture, use and disposal [54].

\subsection{Life Cycle Assessment}

LCA provides a well-established and comprehensive methodology to compare RE (including biofuels) technologies with fossil-based and nuclear energy technologies [10]. The methodology has been evolving since the late 1960s [55] and is now supported by international initiatives [56,57] and governed by standards by the ISO [58]. Importantly, though, the ISO never aimed to standardize LCA methods, and there is no single method for conducting LCA [58].

Policies for climate change mitigation are increasingly being informed by the results of GHG-LCAs of alternative energy carriers and delivery pathways. GHG-LCAs are of particular relevance to the biofuel sector because, within the EU, incentives (in the form of obligation certificates) are expected to be related to the life cycle GHG savings relative to conventional fossil fuels [59].

The current use of GHG-LCA for biofuel carbon reporting tends not to distinguish between two different LCA approaches: ALCA and CLCA [10,59-64]. ALCA provides information about the impacts of the processes used to produce (and consume and dispose of) a product, but does not consider indirect effects arising from changes in the output of a product. ALCA generally provides information on the average unit of product and is useful for consumption-based carbon accounting. It informs comparisons between the direct impacts of products and is used to identify opportunities for reducing direct impacts in different parts of the life cycle. CLCA provides information about the consequences of changes in the level of output (and consumption and disposal) of a product, including effects both inside and outside the life cycle of the product. CLCA models the causal relationships originating from the decision to change the output of the product, and therefore seeks to inform policymakers on the broader impacts of policies, which are intended to change levels of production.

Whereas ALCAs are generally based on stoichiometric relationships between inputs and outputs, and the results may be produced with known levels of accuracy and precision, CLCAs are highly dependent upon economic models representing relationships between demand for inputs, price 
elasticities, supply and markets effects of co-products. Such models rarely provide known levels of accuracy or precision and should therefore be interpreted with caution [60].

The majority of the available literature on energy technologies is based on ALCAs [10]. A resulting key limitation is that energy system changes that might result from the decision to install additional renewable capacity are excluded.

There is, however, substantial variability in published LCA results. Such variability is due to failure to distinguish between ALCA and CLCA, changing characteristics of the background energy system (e.g., its carbon intensity), technology characteristics (e.g., design, capacity factor, variability, service lifetime and vintage), geographic location, data source type (empirical or theoretical), the potential for double counting when assessing large interconnected energy systems, differences in LCA technique (e.g., process-based LCA or input-output LCA) and key methods and assumptions (e.g., co-product allocation, avoided emissions, study scope, etc.) [10]. Moreover, there is a need to take into account more types of externalities (economic and social impacts) and more mechanisms (rebound effects, human behavior, price effects, market dynamics, etc.) to meet the shortcomings of existing LCA studies in the field of, for example, biofuels [55].

Inconsistencies when dealing with system boundaries pose a particular problem with LCA; decisions on including or excluding processes in an analysis are typically not made on a scientific basis [65]. Typically speaking; life cycle inventories (one particular stage in LCA) based on process flow diagrams have an appropriate level of detail and aggregation in the preliminary foreground tiers; but because of the exponential nature of the preceding production flows; this level of detail and certainty decreases further upstream. Therefore; the hybridization of LCA with an input-output macro-economic model (LCA-IO) has received increased interest in the field of industrial ecology as a means of clearly solving the inconsistencies described above.

The application of input-output model in the environmental assessment of products and services was first raised by Wassily Leontief [66] and was further developed and supported by Duchin [67], among others. These initial formulations have since evolved, with the aim of integrating challenges resulting from international trade, so-called MRIO models [68], and from the evaluation of waste management scenarios [69].

One of the more recent iterations formulated by Duchin is WTM. This model is suitable for analyzing scenarios about actions that could be taken to achieve the environmental and social objectives associated with sustainable development. Duchin has additionally proposed that the WTM is suitable for evaluating the adoption of biomass-based fuels. With this said, there are some challenges and potential pitfalls associated with this methodology choice, particularly those associated with the highly aggregated nature of IO tables. The proposed LCA-IO promises to combine the detail of the LCA foreground model with the depth of the background IO.

Another extension to or variation of the LCA is WIO, which attempts to take into account the interdependence in the dynamic flow of products and waste [69], and can be implemented to ascertain the environmental impact of various forms of waste and waste treatment on the whole life cycle of a process, an option lacking in previous iterations of IO-type analysis that focus only on products. This methodological development reflects societies' emerging awareness and follows the holistic ideological thread of industrial ecology. 
Starting in 2010, we entered the "decade of the LCSA" [55,70-73]. LCSA broadens the scope of current LCA from mainly environmental impacts to cover more dimensions of sustainability. It also broadens the scope from predominantly product-related (micro level) questions to questions related to sector (meso level) or even economy-wide (macro level) levels. In addition, it deepens current LCA to include more than just technological relations, for example, physical relations (including limitations in available resources and land), economic and behavioral relations, and other factors. LCA-IO, MRIO, WTM and WIO all provide important input to the development of LCSA.

We agree that LCSA could be an important tool in assessing the sustainability of biofuels. We also argue that the theory and development of LCSA are currently immature. Further development of LCSA should pay particular attention to two points. First, the "dimensions of sustainability" referred to by Guinée et al. [55] must be derived from the main dimensions of sustainable development and sustainable transport as described above. Second, broadening and deepening the scope of analysis may well create a model that is far too complex to use, understand and interpret.

\section{Conclusion}

Increased use of biofuels is high on the sustainable transport policy agenda. However, rather than take this relation for granted, policies must carefully consider biofuels in terms of their compliance with key characteristics and criteria at six levels. (1) The use of biofuels must comply with the four main dimensions of sustainable development. (2) The use of biofuels must comply with the four main dimensions of sustainable transport. (3) A biofuels strategy must compare favorably with other sustainable transport strategies, such as changing transport patterns and reducing transport volume. (4) Gains from a biofuels strategy must compare favorably to gains from improving fossil-fuel-based advanced ICE vehicles. (5) Benefits from the use of bio-fuelled vehicles must compare favorably to those from the use of other alternative-fuelled vehicles. (6) Benefits from the use of first-generation biofuels must compare favorably to those from the use of next-generation biofuels. In addition, developing robust and scientific sustainability criteria demands a reliable theoretical perspective and a well-established methodological base. Industrial ecology theory and life cycle sustainability assessment methodology, respectively, should prove very useful in that regard.

Achieving sustainable transport will most probably require a full portfolio of strategies. No single strategy such as improving public transport, reducing traffic volumes, or increasing the use of biofuels, plug-in hybrids and long-range-battery electric vehicles will achieve it. Thus, we agree with Sandy Thomas [74], who stated "The triple threats of global warming, energy security and urban air pollution are too great to rely on any one transportation option [strategy or fuels] for the foreseeable future.”

\section{Acknowledgments}

The authors would like to acknowledge Sogn og Fjordane Energi and the CenSES program for their financial support of the study.

\section{Conflict of Interest}

The authors declare no conflict of interest. 


\section{References and Notes}

1. UNEP. Towards a Sustainable Production and Use of Resources: Assessing Biofuels; United Nations Environmental Programme: Nairobi, Kenya, 2009.

2. Strategies also include policy instruments to warrant their implementation, such as information-based, control- and command-based and marked-based instruments. We do not, however, discuss these instruments further in this article.

3. O’Riordan, T. The Politics of Sustainability. In Sustainable Environmental Economics and Management; Turner, K.R., Ed.; Wiley: Chichester, UK, 1993; pp. 37-69.

4. Lafferty, W.M. Governance for Sustainable Development. The Challenge of Adapting Form to Function; Elgar: Cheltenham, UK, 2004; p. 26.

5. WCED (World Commission on Environment and Development). Our Common Future; Oxford University Press: Oxford, UK, 1987.

6. Following this logic, we contend that economic growth is not one of the main dimensions of sustainable development. This argument runs contrary to the popular "triple bottom line" model focusing on the balance between environmental, social and economic issues, a model that presently dominates the academic debate on sustainable development. However, aspiring for economic growth may be equivalent to aspiring for an improved standard of living far beyond what can be considered ecologically sustainable in the long term. The Brundtland Report claims that: "Sustainable development clearly requires economic growth in places where such [human] needs are not being met. Elsewhere, it can be consistent with economic growth, provided the content of growth reflects the broad principles of sustainability and non-exploitation of others. But growth by itself is not enough” ([5], p. 44). Thus, we argue, economic growth is a potential means to facilitate the fulfilment of the four main dimensions.

7. Daly, H. Ecological Economics and Sustainable Development, Selected Essays of Herman Daly; Elgar: Cheltenham, UK, Northampton, MA, USA, 2007.

8. Høyer, K.G. Sustainable mobility-The concept and its implications. Ph.D. Dissertation, Western Norway Research Institute, Sogndal, Norway, 2000.

9. Fenton, P.; Carlsson, H. BioEthanol for Sustainable Transport. Results and recommendations from the European BEST project. Available online: http://www.best-europe.org/upload/ BEST_documents/info_documents/BEST_FinalReport_revfeb10.pdf (accessed on 12 June 2013).

10. IPCC. Renewable Energy Sources and Climate Change Mitigation; Special Report of the Intergovernmental Panel on Climate Change; Cambridge University Press: New York, NY, USA, 2011.

11. Diaz-Chavez, R.A. Assessment of Existing Socioeconomic Principles, Criteria and Indicators for Biomass Production and Conversion; Report of the FP7 Global-Bio-Pact Project; Imperial College: London, UK, 2010.

12. In the Green Paper, the EU used the term "sustainable mobility". Applying the imperative of sustainable development to the transport sector, however, has led to several concepts denoted by terms such as sustainable transport, sustainable mobility, sustainable transportation, sustainable transport systems and sustainability issues in transport. In the literature on transport and sustainable development, these terms are essentially synonymous. Variants of "sustainable 
transport" seem to be the preferred terms in North America, whereas "sustainable mobility" variants are preferred in Europe [27]. We use the term "sustainable transport" in this article.

13. CEC. A Community Strategy for "Sustainable Mobility"; Green Paper on the Impact of Transport on the Environment; COM (92) 46 Final; Commission of the European Communities: Brussels, Belgium, 1992.

14. CEC. European Transport Policy for 2010: Time to Decide; White paper, COM (2001) 370 Final; Commission of the European Communities: Brussels, Belgium, 2001.

15. CEC. Roadmap to a Single European Transport Area-Towards a Competitive and Resource Efficient Transport System; White paper, COM (2011) 144 Final; Commission of the European Communities: Brussels, Belgium, 2011.

16. Black, W.R. Sustainable Transportation: Problems and Solutions; Guilford Press: New York, NY, USA, 2010.

17. Schiller, P.L.; Bruun, E.C.; Kenworthy, J.R. An Introduction to Sustainable Transportation: Policy, Planning, and Implementation; Earthscan: London, UK, 2010.

18. Castillo, H.; Pitfield, D.E. ELASTIC—A methodological framework for identifying and selecting sustainable transport indicators. Transp. Res. Part D 2010, 15, 179-188.

19. Holden, E. Achieving Sustainable Mobility: Everyday and Leisure-Time Travel in the EU; Ashgate: Aldershot, UK, 2007.

20. Litman, T.; Burwell, D. Issues in sustainable transportation. Glob. Environ. Issues 2006, 6, 331-347.

21. Banister, D. Unsustainable Transport; Routledge: London, UK, 2005.

22. IEA. Transport, Energy and $\mathrm{CO}_{2}$ : Moving Toward Sustainability; International Energy Agency: Paris, France, 2009.

23. Julia, R.; Duchin, F. World trade as the adjustment mechanism of agriculture to climate change. Clim. Change 2007, 82, 393-409.

24. However, substantial gray areas exist between the strategies; in practical policy, the three strategies will likely overlap. Nevertheless, each strategy reflects its main area of interest; furthermore, differentiating between the three strategies for achieving sustainable transport facilitates analysis.

25. $\mathrm{I}=\mathrm{P} \times \mathrm{A} \times \mathrm{T}$. Human Impact $(\mathrm{I})$ on the environment equals the product of $\mathrm{P}=$ Population, $\mathrm{A}=$ Affluence, $\mathrm{T}=$ Technology. ASIF: $\mathrm{CO}_{2}=$ Activity $*$ Structure $*$ Intensity $*$ Fuels. ASI-Avoid, shift, improve. SMART: $S M=g(A, R, T)$ where $S M=$ sustainable mobility, $\mathrm{A}=$ changing transport patterns and public transport use, $\mathrm{R}=$ reducing growth in transport, and $\mathrm{T}=$ increasing pace of technological change. STPM index: based on the difference between the level of sustainable mobility and the level of potential mobility, standardized by population size and units of measurement.

26. Commoner, B. The Environmental Cost of Economic Growth. In Population, Resources and the Environment; Government Printing Office: Washington, DC, USA, 1972; pp. 339-363.

27. Ehrlich, P.R.; Holdren, J.P. Impact of Population Growth. Science 1971, 171, 1212-1217.

28. Schipper, L.; Lilliu, C.M. Transportation and $\mathrm{CO}_{2}$ Emissions: Flexing the Link. A Path for the World Bank; The World Bank: Washington, DC, USA, 1999. 
29. Dalkmann, H.; Brannigan, C. Transport and Climate Change; Sourcebook Module 5e, GTZ: Eschborn, Geramny, 2007.

30. Sager, J.; Apte, J.S.; Lemoine, D.M.; Kammen, D.M. Reduce growth rate of light-duty vehicle travel to meet 2050 global climate goals. Environ. Res. Lett. 2011, doi:10.1088/1748-9326/6/2/024018.

31. Black, W.R. Transportation: A Geographical Analysis; Guilford Press: London, UK, 2003.

32. Travel by plane is also a collective form of transport, but its high energy consumption per passenger kilometer makes travel by plane comparable to travel by car in that regard.

33. OECD. Environmentally Sustainable Transport, futures, strategies and best practices, Synthesis Report of the OECD project on Environmentally Sustainable Transport EST, presented on occasion of the International est! Conference, 4th to 6th October, Vienna, Austria, Organisation for Economic Co-operation and Development.

34. IEA. Energy Technology Perspectives 2008-In support of the G8 Plan of Action-Scenarios and Strategies for 2050; International Energy Agency: Paris, France, 2008.

35. OECD. Globalisation, Transport and the Environment; Organisation for Economic Co-operation and Development: Paris, France, 2010.

36. IEA. World Energy Outlook 2010; International Energy Agency: Paris, France, 2010.

37. McGill, R.; Aakko-Saksa, P.; Nylund, N.-O. Final Report-Analysis of Biodiesel Options; IEA Advanced Motor Fuels Implementing Agreement; International Energy Agency: Paris, France, 2009.

38. Lü, J.; Sheahan, C.; Fu, P. Metabolic engineering of algae for fourth generation biofuels production. Energy Environ. Sci. 2011, 4, 2451-2466.

39. Graham-Rowe, D. Agriculture: Beyond food versus fuel. Nature 2011, 474, S6-S8.

40. Gressel, J. Transgenics are imperative for biofuel crops. Plant Sci. 2008, 174, 246-263.

41. Chapotin, S.M.; Wolt, J. Genetically modified crops for the bioeconomy: Meeting public and regulatory expectations. Transgenic Res. 2007, 16, 675-688.

42. Firbank, L. Assessing the ecological impacts of bioenergy projects. BioEnergy Res. 2008, 1, 12-19.

43. Warwick, S.I.; Beckie, H.J.; Hall, L.M. Gene flow, invasiveness, and ecological impact of genetically modified crops. Ann. N. Y. Acad. Sci. 2009, 1168, 72-99.

44. Euractiv. Biofuels: The Next Generation. Available online: http://www.euractiv.com/en/energy/ biofuels-generation/article-165951 (accessed on 25 July 2012).

45. IEE. Eyes on the Track, Mind on the Horizon-From Inconvenient Rapeseed to Clean Wood: A European road Map for Biofuels; Intelligent Energy Europe: Brussels, Belgium, 2008.

46. McGill, R. Algae as a Feedstock for Transport Fuels-the Future of Biofuels? A White Paper Prepared for the IEA Advanced Motor Fuels Implementing Agreement; Presented to the 35th Executive Committee Meeting; Vienna, Austria, 2008.

47. EC. Directive 2009/28/EC of the European Parliament and of the Council of 23 April 2009 on the promotion of the use of energy from renewable sources and amending and subsequently repealing Directives 2001/77/EC and 2003/30/EC. Available online: http://eur-lex.europa.eu/LexUriServ/ LexUriServ.do?uri=Oj:L:2009:140:0016:0062:en:PDF (accessed on 17 July 2013).

48. EISA. Energy Independence and Security Act of 2007; Public Law 110-140; 110th Congress, U.S. Government Printing Office: Washington, DC, USA, 19 December 2007. 
49. Direct land-use change (dLUC) occurs when bioenergy feedstock production modifies an existing land use, resulting in a change in above- and below-ground carbon stocks. Indirect LUC (iLUC) occurs when a change in the production level of an agricultural product (i.e., a reduction in food or feed production induced by agricultural land conversion to produce a bioenergy feedstock) leads to a market-mediated shift in land management activities (i.e., dLUC) outside the region of primary production expansion. iLUC is not directly observable, and is complex to model and difficult to attribute to a single cause because multiple actors, industries, countries, policies and markets dynamically interact [19] (p. 50).

50. Van Dam, J.; Junginger, M.; Faaij, A.P.C. From the global efforts on certification of bioenergy towards an integrated approach based on sustainable land-use planning. Renew. Sustain. Energy Rev. 2010, 14, 2445-2472.

51. There is also a "temporal transfer effect" to consider regarding alternative energy. It is essentially an effect occurring when customers use their own electricity generation to offset consumption over a period by allowing their electric meter to spin backwards at times when generation exceeds demand. This transfer effect does not pertain to biofuels.

52. Huo, H.; Wu, Y.; Wang, M. Total versus urban: Well-to-wheels assessment of criteria pollutant emissions from various vehicle/fuel systems. Atmosp. Environ. 2009, 43, 1796-1904.

53. Frosch, R.A. Industrial ecology: A philosophical introduction. Proc. Natl. Acad. Sci. USA 1992, 89, 800-803.

54. Kumar, C.; Patel, N. Industrial ecology. Proc. Natl. Acad. Sci. USA 1992, 89, 798-799.

55. Guinée, J.B.; Heijungs, R.; Huppes, G.; Zamagni, A.; Masoni, P.; Buonamici, R.; Ekvall, T.; Rydberg, T. Life cycle assessment: Past, present, and future. Environ. Sci. Technol. 2011, 45, 90-96.

56. In 2002, the United Nations Environment Programme (UNEP) and the Society for Environmental Toxicology and Chemistry (SETAC) launched an International Life Cycle Partnership known as the Life Cycle Initiative: Life Cycle Initiative website, United Nation Environment Programme. Available online: http://lcinitiative.unep.fr/ (accessed on 28 June 2012).

57. In 2005, the European Commission established the European Platform on Life Cycle Assessment: European Platform on Life Cycle Assessment (LCA). Available online: http://lct.jrc.ec.europa.eu/ (accessed on 28 June 2012).

58. There are currently two international LCA standards: ISO 14040. Environmental managementLife cycle assessment-Principles and framework, International Organization for Standardization, Geneva; ISO 14044. Environmental management-Life cycle assessment-Requirements and guidelines, International Organization for Standardization, Geneva.

59. Brander, M.; Tipper, R.; Hutchison, C.; Davis, G. Consequential and Attributional Approaches to LCA: A Guide to Policy Makers with Specific Reference to Greenhouse Gas LCA of Biofuels; Technical Paper TP-090403-A; Ecometrica Press: London, UK, 2009.

60. Thomassen, M.A.; Dalgaard, R.; Heijungs, R.; de Boer, I. Attributional and consequential LCA of milk production. Int. J. Life Cycle Assess 2008, 13, 339-349.

61. Heijungs, R. Economic Drama and the Environmental Stage Formal Derivation of Algorithmic Tools for Environmental Analysis and Decision-Support from a Unified Epistemological Principle; Centre of Environmental Science, Leiden University: Leiden, The Netherlands, 1997. 
62. Rebitzer, G.; Ekvall, T.; Frischknecht, R.; Hunkeler, D.; Norris, G.; Rydberg, T.; Schmidt, W.P.; Suh, S.; Weidema, B.P.; Pennington, D.W. Life cycle assessment. Part 1: framework, goal and scope definition, inventory analysis, and applications. Environ. Int. 2004, 30, 701-720.

63. Weidema, B.P. Market Information in Life Cycle Assessment; Environmental Project No. 863 2003; Danish Environment Protection Agency: Copenhagen, Denmark, 2003; pp. 1-147.

64. Finnveden, G.; Hauschild, M.Z.; Ekvall, T.; Guinee, J.; Heijungs, R.; Hellweg, S.; Koehler, A.; Pennington, D.; Suh, S. Recent developments in Life Cycle Assessment. J. Environ. Manag. 2009, 91, 1-21.

65. Suh, S.; Lenzen, M.; Treloar, G.J.; Hondo, H.; Horvath, A.; Huppes, G.; Jolliet, O.; Klann, U.; Krewitt, W.; Moriguchi, Y.; Munksgaard, J.; Norris, G. System boundary selection in life-cycle inventories using hybrid approaches. Environ. Sci. Technol. 2004, 38, 657-664.

66. Leontief, W. Structure of the World Economy: Outline of a simple input-output formulation. Proc. IEEE 1975, 63, 345-351.

67. Duchin, F. Input-output Analysis and Industrial Ecology. In The Greening of Industrial Ecosystems; Allenby, B.R., Richards, D.J., Eds.; National Academy Press: Washington, DC, USA, 1994; pp. 61-68.

68. Peters, G.P.; Hertwich, E.G. The application of multi-regional input-output analysis to industrial ecology: Evaluating trans-boundary environmental impacts. Handb. Input-Output Econ. Ind. Ecol. 2009, 23, 847-863.

69. Nakamura, S.; Kondo, Y. Input-output analysis of waste management. J. Ind. Ecol. 2002, 6, 39-63.

70. Zamagni, A.; Guinée, J.; Heijungs, R.; Masoni, P. Life Cycle Sustainability Analysis. In Life Cycle Assessment Handbook: A Guide for Environmentally Sustainable Products; Curran, M.A., Ed.; Wiley-Scrivener: Salem, MA, USA, 2012.

71. Guinée, J.; Heijungs, R. Life cycle sustainability analysis: Framing questions for approaches. J. Ind. Ecol. 2011, 15, 656-658.

72. Hertwich, E.G. Life cycle approaches to sustainable consumption: A critical review. Environ. Sci. Technol. 2005, 39, 4673-4684.

73. Kloepffer, W. Life Cycle Sustainability Assessment of Products (LCAS). Int. J. Life Cycle Assess. 2008, 13, 89-95.

74. Thomas, C.E.S. Transportation options in a carbon-constrained world: Hybrids, plug-in hybrids, biofuels, fuel cell electric vehicles, and battery electric vehicles. Int. J. Hydrogen Energy 2009, 34, 9279-9296.

(C) 2013 by the authors; licensee MDPI, Basel, Switzerland. This article is an open access article distributed under the terms and conditions of the Creative Commons Attribution license (http://creativecommons.org/licenses/by/3.0/). 